\title{
Microfluidic Platform for Assessment of Therapeutic Proteins Using Molecular Charge Modulation Enhanced Electrokinetic Concentration Assays
}

\author{
Wei Ouyang ${ }^{1}$, Sung Hee Ko ${ }^{1}$, Di Wu ${ }^{2}$, Annie Yu Wang ${ }^{2}$, Paul W. Barone ${ }^{3}$, William S. \\ Hancock $^{2}$, and Jongyoon Han ${ }^{1,4, *}$ \\ ${ }^{I}$ Department of Electrical Engineering and Computer Science, ${ }^{3}$ Center for Biomedical Innovation and \\ ${ }^{4}$ Department of Biological Engineering, Massachusetts Institute of Technology, Cambridge, MA 02139, \\ USA \\ ${ }^{2}$ Barnett Institute and Department of Chemistry and Chemical Biology, Northeastern University, Boston, \\ MA 02115, USA
}

\section{Supporting Information}




\section{SI-1. Molecular properties of hGH, IFNa2b, G-CSF and their receptors}

hGH, IFN $\alpha 2 b$, and G-CSF represent three important categories of TPs - recombinant hormones, interferons and growth factors, respectively. The sequences of the three TPs can be obtained from the NCBI library of proteins (http://www.ncbi.nlm.nih.gov/protein).

The sequence of hGH is:

MFPTIPLSRL FDNAMLRAHR LHQLAFDTYQ EFEEAYIPKE QKYSFLQNPQ TSLCFSESIP 60

TPSNREETQQ KSNLELLRIS LLLIQSWLEP VQFLRSVFAN SLVYGASDSN VYDLLKDLEE 120

GIQTLMGRLE DGSPRTGQIF KQTYSKFDTN SHNDDALLKN YGLLYCFRKD MDKVETFLRI 180

VQCRSVEGSC GF 192

The sequence of IFN $\alpha 2 b$ is:

CDLPQTHSLG SRRTLMLLAQ MRRISLFSCL KDRHDFGFPQ EEFGNQFQKA ETIPVLHEMI 60

QQIFNLFSTK DSSAAWDETL LDKFYTELYQ QLNDLEACVI QGVGVTETPL MNEDSILAVR 120

KYFQRITLYL KEKKYSPCAW EVVRAEIMRS FSLSTNLQES LRSKE 165

The sequence of G-CSF is:

TPLGPARSLP QSFLLKCLEQ VRKIQADGAE LQERLCATHK LCHPEELVLL GHSLGIPQAP 1

LSSCSSQSLQ LTSCLDQLHG GLFLYQGLLQ ALAGISPELA PTLDTLQLDV TDFATNIWLQ 60

MEDLGVAPAV QPTQGTMPTF TSAFQRRAGG VLVASQLQRF LGLAYRGLRY LAEP 174

The sequence of hGH receptor from Acrobiosystems (catalog \#: GHR-H5222) is:

AILSRAPWSL QSVNPGLKTN SSKEPKFTKC RSPERETFSC HWTDEVHHGT KNLGPIQLFY 60

TRRNTQEWTQ EWKECPDYVS AGENSCYFNS SFTSIWIPYC IKLTSNGGTV DEKCFSVDEI 120

VQPDPPIALN WTLLNVSLTG IHADIQVRWE APRNADIQKG WMVLEYELQY KEVNETKWKM 180

MDPILTTSVP VYSLKVDKEY EVRVRSKQRN SGNYGEFSEV LYVTLPQMSQ FTCEEDFYHH 240

HHHH 244 
The sequence of IFN $\alpha 2 \mathrm{~b}$ receptor from Sino Biological (catalog \#: 10359-H08H) is:

ISYDSPDYTD ESCTFKISLR NFRSILSWEL KNHSIVPTHY TLLYTIMSKP EDLKVVKNCA 60

NTTRSFCDLT DEWRSTHEAY VTVLEGFSGN TTLFSCSHNF WLAIDMSFEP PEFEIVGFTN 120

HINVMVKFPS IVEEELQFDL SLVIEEQSEG IVKKHKPEIK GNMSGNFTYI IDKLIPNTNY 180

CVSVYLEHSD EQAVIKSPLK CTLLPPGQES ESAESAKHHН НHНHНHНH 228

The sequence of G-CSF receptor from Acrobiosystems (catalog \#: GCR-H5223-100ug) is: CGHISVSAPI VHLGDPITAS CIIKQNCSHL DPEPQILWRL GAELQPGGRQ QRLSDGTQES 60

IITLPHLNHT QAFLSCCLNW GNSLQILDQV ELRAGYPPAI PHNLSCLMNL TTSSLICQWE 120

PGPETHLPTS FTLKSFKSRG NCQTQGDSIL DCVPKDGQSH CCIPRKHLLL YQNMGIWVQA 180

ENALGTSMSP QLCLDPMDVV KLEPPMLRTM DPSPEAAPPQ AGCLQLCWEP WQPGLHINQK 240

CELRHKPQRG EASWALVGPL PLEALQYELC GLLPATAYTL QIRCIRWPLP GHWSDWSPSL 300

ELRTTERAPT VRLDTWWRQR QLDPRTVQLF WKPVPLEEDS GRIQGYVVSW RPSGQAGAIL 360

PLCNTTELSC TFHLPSEAQE VALVAYNSAG TSRPTPVVFS ESRGPALTRL HAMARDPHSL 420

WVGWEPPNPW PQGYVIEWGL GPPSASNSNK TWRMEQNGRA TGFLLKENIR PFQLYEIIVT 480

PLYQDTMGPS QHVYAYSQEM APSHAPELHL KHIGKTWAQL EWVPEPPELG KSPLTHYTIF 540

WTNAQNQSFS AILNASSRG VLHGLEPASL YHIHLMAASQ AGATNSTVLT LMTLTPHHHH 600

HH 602

Based on the sequences above and specifications from vendors, the molecular weights of the six proteins are summarized in Table SI-1-A. The actual molecular weights of receptors are larger than calculated due to glycosylation.

A. Molecular weights of hGH, IFN alpha-2b, G-CSF and their receptors. 


\begin{tabular}{|c|c|c|c|}
\hline \multirow{2}{*}{1} & Molecule & $\begin{array}{c}\text { Calculated } \\
\text { MW (kDa) }\end{array}$ & $\begin{array}{c}\text { Actual MW } \\
(\mathrm{kDa})\end{array}$ \\
\hline \multirow{2}{*}{2} & hGH & 22.2 & \\
\cline { 2 - 4 } & GHR & 28.5 & $\sim 45$ \\
\hline & IFN $22 \mathrm{~b}$ & 19.3 & \\
\hline \multirow{2}{*}{3} & IFNR & 26.3 & $\sim 45$ \\
\cline { 2 - 4 } & G-CSF & 18.8 & \\
\cline { 2 - 4 } & GCSFR & 67.2 & $\sim 94$ \\
\hline
\end{tabular}

\section{SI-2. Design of the positive mobility modulator}

For pMCM to work, the positively modulated receptor has to be positively charged and unconcentratable, while the TP-TPR complex has to be negatively charged and concentratable. In other words, the following relations have to be satisfied: $Q$ (peptide) $+\mathrm{Q}(\mathrm{TPR})>0$, $\mathrm{Q}($ peptide $)+\mathrm{Q}(\mathrm{TPR})+\mathrm{Q}(\mathrm{TP})<0$. Therefore the charge of the mobility modulator, peptide, has to be: $-\mathrm{Q}(\mathrm{TP})<\mathrm{Q}$ (peptide $)<-\mathrm{Q}(\mathrm{TP})-\mathrm{Q}(\mathrm{TPR})$. To design a peptide with the appropriate number of charges for modulating GHR, IFNR, and GCSFR, we performed a theoretical estimation based on the charges of hGH, IFN $22 \mathrm{~b}, \mathrm{G}-\mathrm{CSF}$ and their receptors. The $\mathrm{pH}$ near the ion depletion region in the EC device is increased to $\sim 8.0$ due to depletion of hydrogen ions. The numbers of charges of each molecules at $\mathrm{pH}=8.0$ were calculated using the sourceforge protein calculator v3.4 (http://protcalc.sourceforge.net). Based on the values calculated, the ranges of the charges of the mobility modulator were obtained (Table SI-2-A). The number of charges that could be used for modulating all the three TP-TPR binding pairs is 14.6. Therefore, the sequence of the peptide was designed as GRGRGRGRGRGRGRGRGRGRGRGRGRGRGRGRGK(5-FAM), which has a net charge of $\sim 14.5$ at $\mathrm{pH}=8.0$.

A. Theoretical calculation of the number of charges of the mobility modulator.

\begin{tabular}{|c|c|c|c|}
\hline \multirow{2}{*}{1} & Molecule & $\begin{array}{c}\text { Charges at } \\
\mathrm{pH} \sim 8.0\end{array}$ & $\begin{array}{c}\text { Range of charges of } \\
\text { mobility modulator }\end{array}$ \\
\hline \multirow{2}{*}{1} & hGH & -6.5 & {$[8.1,14.6]$} \\
\cline { 2 - 3 } & GHR & -8.1 & -4.5 \\
\cline { 2 - 3 } 2 & IFN 2 2b & -14.6 & {$[14.6,19.1]$} \\
\cline { 2 - 3 } & IFNR & \multicolumn{2}{|c}{} \\
\hline
\end{tabular}




\begin{tabular}{|l|c|c|c|}
\hline \multirow{3}{*}{3} & G-CSF & -5.6 & \multirow{2}{*}[12.4,18.0]{} \\
\cline { 2 - 3 } & GCSFR & -12.4 & \\
\hline
\end{tabular}

\section{SI-3. Design of the negative mobility modulator}

The EC device has limited charge-based separation resolution: highly charged molecules (e.g. DNA) could be easily separated from minimally charged molecules (e.g. proteins), but it cannot separate between molecules with slightly different mobilities(e.g. different protein species). The mobility of biomolecules could be estimated by the charge-mass ratio: $Q / M$, where $\mathrm{Q}$ is the number of charges, and $\mathrm{M}$ is the molecular weight in $\mathrm{kDa}$. The mobility of oligonucleotides is constant, which is $\sim 1 / 0.3=3.3$. The mobility of GHR, IFNR IFN $\alpha 2 b$, and GCSF are $8.1 / 45=0.18,14.6 / 45=0.32,12.4 / 94=0.13$, based on Tables SI-1-A and SI-2-A. To sufficiently increase the mobility of receptors, an oligonucleotide with 64 bases and a molecular weight of $20 \mathrm{kDa}$ was designed for conjugation. The sequence is 5'- $\mathrm{NH}_{2}$-AGCT AGCT AGCT AGCT AGCT AGCT AGCT AGCT AGCT AGCT AGCT AGCT AGCT AGCT AGCT AGCT 3', with a C-12 amino modifier at 5'. In the EC device, it is a good estimation that molecules (the TP-TPR complex in this study) with mobility $>1.0$ could be easily separated from proteins (unbound TP). In Table SI-3-A, we calculated the mobility of receptors in respect to degrees of conjugation with the oligonucleotide designed. For GHR and IFNR, there should be a minimum DoC of 1.0 to separate the complex and unbound TP. For GCSFR, which is heavier, there should be a minimum DoC of 2.0. For better separation resolution, higher DoCs are desirable, on the condition that the bioactivity of the receptor is not affected due to high degrees of modification.

A. Mobility of negatively modulated receptors v.s. degree of conjugation by calculation.

\begin{tabular}{|c|c|c|c|c|c|}
\hline \multirow{2}{*}{ Mobility } & \multicolumn{5}{|c|}{ DoC } \\
\cline { 2 - 6 } & $\mathbf{0}$ & $\mathbf{1 . 0}$ & $\mathbf{2 . 0}$ & $\mathbf{3 . 0}$ & $\mathbf{4 . 0}$ \\
\hline GHR & 0.18 & 1.11 & 1.60 & 1.91 & 2.11 \\
\hline IFNR & 0.32 & 1.21 & 1.68 & 1.97 & 2.16 \\
\hline GCSFR & 0.13 & 0.67 & 1.05 & 1.33 & 1.54 \\
\hline
\end{tabular}

\section{SI-4. Determination of degree of conjugation (DoC)}


DoC is defined as the number of mobility modulator molecule per receptor molecule, which was used for the quantification and optimization of MCM. DoC was obtained by measuring the molar concentration of receptor molecule in a sample and the molar concentration of mobility modulator molecule attached to receptor molecules. The weight concentration of receptor molecule was measured by BCA protein assay and converted to molar concentration by being divided by the molecular weight of receptor. The molar concentration of attached mobility modulator molecule was represented by the molar concentration of the conjugation bond, assuming each mobility modulator molecule was attached to a receptor molecule by only one conjugation bond. In this work, the HyNic-4FB conjugation chemistry yielded a UV-traceable bond, which absorbed at $354 \mathrm{~nm}$ and had a molar extinction coefficient of 29,000. Through measuring the $354 \mathrm{~nm}$ absorption of a sample by spectrophotometry and further dividing it by the bond's molar extinction coefficient, the molar concentration of the conjugation bond and in turn that of the mobility modulator was obtained. DoC was calculated by dividing the molar concentration of mobility modulator molecule by the molar concentration of receptor molecule.

\section{SI-5. Experiment procedures of MCM}

Positive MCM was realized by receptor-peptide conjugation. Receptor was reconstituted to 1 $\mathrm{mg} / \mathrm{ml}$ in $1 \times$ PBS, followed by incubation with Sulfo-S-4FB at a molar ratio of 1:20 at room temperature for 2 hours. After desalting the receptor with Zeba ${ }^{\mathrm{TM}}$ Spin Desalting Columns, the concentration of receptor was measured by BCA protein assay. $2 \mu \mathrm{L}$ S-4FB modified receptor was incubated with $18 \mathrm{uL} 0.5 \mathrm{mM} \mathrm{2-Hydrazinopyridine} \mathrm{at} 37^{\circ} \mathrm{C}$ for 1 hour, which generated a compound with absorption at $350 \mathrm{~nm}$. Based on the absorption measured by NanoDrop 1000 and the concentration of receptor, molar substitution ration (MSR) of S-4FB modification was determined. If $\mathrm{MSR}=4-10$, there are sufficient conjugation sites for HyNic-peptide; otherwise, receptor modification should be repeated until obtaining $\mathrm{MSR}=4-10$. S-4FB modified receptor was incubated with HyNic-peptide at molar ratios of $1: 3$, at $4^{\circ} \mathrm{C}$ overnight. After desalting, the concentration of the receptor-peptide conjugate was measured by BCA protein assay. Based on the absorption at $354 \mathrm{~nm}$ measured by NanoDrop 1000 and the concentration of conjugate, the DoCs were determined. Negative MCM was realized by receptor-oligonucleotide conjugation. Oligonucleotide was resuspended to $0.5 \mathrm{OD}_{260} / \mathrm{uL}$, and receptor was reconstituted to $1 \mathrm{mg} / \mathrm{ml}$. Oligonucleotide was incubated with S-4FB at a molar ratio of 1:20 at room temperature for 2 hours. Receptor was incubated with S-HyNic at a molar ratio of 1:20 at room temperature for 2.5 hours. After desalting, the concentration of S-4FB modified oligonucleotide was measured by A260 absorption, and the concentration of S-HyNic modified receptor was measured by BCA protein assay. $2 \mu \mathrm{L}$ S-4FB modified oligonucleotide was incubated with $18 \mathrm{uL} 0.5 \mathrm{mM} 2-$ 
Hydrazinopyridine at $37^{\circ} \mathrm{C}$ for 1 hour, which generated a compound with absorption at $350 \mathrm{~nm} .2$ $\mu \mathrm{L}$ S-HyNic modified receptor was incubated with $18 \mathrm{uL} 0.5 \mathrm{mM}$ 2-Sulfobenzaldehyde at $37^{\circ} \mathrm{C}$ for 1 hour, which generated a compound with absorption at $348 \mathrm{~nm}$. Based on absorption and concentration, the MSRs of S-4FB modified oligonucleotide and S-HyNic modified receptor were determined. If the MSR of S-4FB modified oligonucleotide was $\sim 1.0$ and the MSR of S-HyNic modified receptor was 4-10, the modifications were successful; otherwise, modifications should be repeated until obtaining correct MSRs. S-HyNic modified receptor was incubated with S-4FB modified oligonucleotide at molar ratios of $1: 14$, at $4^{\circ} \mathrm{C}$ overnight. After desalting, the concentration of the receptor-peptide conjugate was measured by BCA protein assay. Based on the absorption at $354 \mathrm{~nm}$ measured by NanoDrop 1000 and the concentration of conjugate, the DoCs were determined.

The mixing ratios of modified receptors and peptides/oligonucleotides were adjusted to achieve optimal DoCs. S-4FB modified receptor was incubated with HyNic-peptide at molar ratios of $1: 1.5,1: 3$, and $1: 6$, at $4^{\circ} \mathrm{C}$ overnight. It was observed that $\mathrm{DoC}=\sim 1.0$ when $\mathrm{S}-4 \mathrm{FB}$ modified receptor:HyNic-peptide=1:3, which was the optimal condition for pMCM (Fig. SI-7-a). S-HyNic modified receptor was incubated with S-4FB modified oligonucleotide at molar ratios of 1:3.5, 1:7.0, and 1:14, at $4^{\circ} \mathrm{C}$ overnight. It was observed that $\mathrm{DoC}$ was higher at higher concentrations of S-4FB modified oligonucleotide (Fig. SI-7-b). The ratio of 1:14 was adopted for nMCM.

(a)

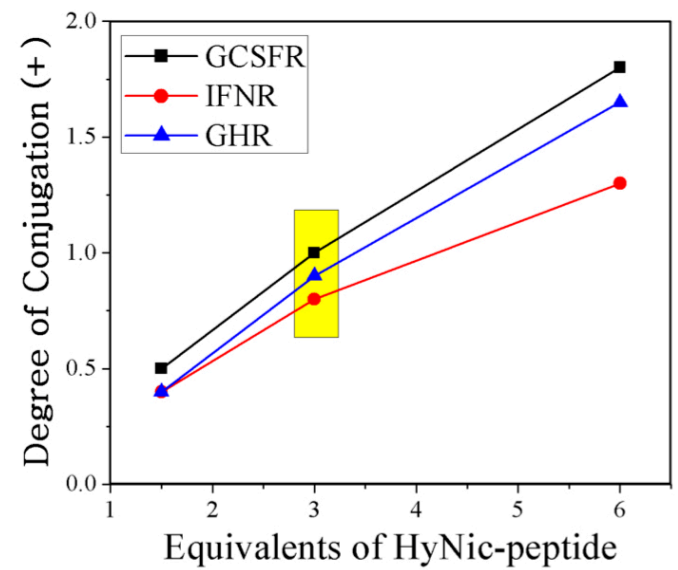

(b)

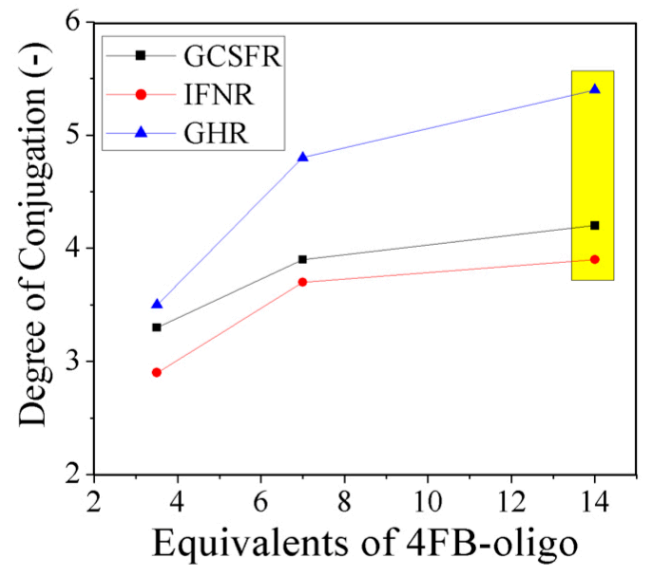

Optimization of (a) positive MCM and (b) negative MCM.

\section{SI-6. Forced degradation of hGH and G-CSF for the degradation-determination assay}

The degradation protocols are as the following. (1) Thermal treatment of hGH and G-CSF: Before thermal treatment, hGH was diluted to $1 \mathrm{mg} / \mathrm{ml}$ using hGH stock buffer. G-CSF was used as delivered $(1.13 \mathrm{mg} / \mathrm{ml}$ in G-CSF stock buffer). Five $50 \mathrm{uL}$ samples of hGH were incubated in water bath for $30 \mathrm{~min}$ at $65^{\circ} \mathrm{C}, 75^{\circ} \mathrm{C}, 85^{\circ} \mathrm{C}, 95^{\circ} \mathrm{C}$, and $100^{\circ} \mathrm{C}$, respectively. Five $50 \mathrm{uL}$ samples of 
G-CSF were incubated in water bath for $30 \mathrm{~min}$ at $30^{\circ} \mathrm{C}, 40^{\circ} \mathrm{C}, 50^{\circ} \mathrm{C}, 60^{\circ} \mathrm{C}$, and $70^{\circ} \mathrm{C}$, respectively. All thermally treated samples were cooled down to room temperature before being used in assays. (2) Light exposure of hGH and G-CSF: Before light treatment, hGH was diluted to $1 \mathrm{mg} / \mathrm{ml}$ using hGH stock buffer. G-CSF was used as delivered $(1.13 \mathrm{mg} / \mathrm{ml}$ in G-CSF stock buffer). A UV transilluminator (Spectrolin $\AA$, model number: TC-365R) with the range of $320 \mathrm{~nm}$ to $400 \mathrm{~nm}$ and a power of $375 \mathrm{Wm}^{-2}$ was used to treat hGH and G-CSF samples. Four $50 \mathrm{uL}$ samples of hGH and four $50 \mathrm{uL}$ samples of G-CSF were exposed in the UV transilluminator for $32,64,128,256 \mathrm{~min}$, which had total energy of $200,400,800,1600 \mathrm{Whm}^{-2}$, respectively. (3) Oxidation of hGH and G-CSF: hGH and G-CSF were used as delivered for artificial oxidation. The oxidized samples were prepared by addition of hydrogen peroxide to give final concentrations of $0.05 \%(\mathrm{v} / \mathrm{v})$ and $0.5 \%(\mathrm{v} / \mathrm{v})$, and then incubation at $37^{\circ} \mathrm{C}$ overnight. (4) Longterm incubation of hGH and G-CSF: Stock hGH and G-CSF were buffer exchanged to sodium borate buffer $(0.1 \mathrm{M}, \mathrm{pH}=9)$. hGH samples were incubated at $37^{\circ} \mathrm{C}$ for 4 weeks and 8 weeks, followed by buffer exchange back to hGH stock buffer. G-CSF samples were incubated at $37^{\circ} \mathrm{C}$ for 1 day, 3 days, and 6 days.

\section{SI-7. Preparation of samples for bioassay}

hGH (Humatrope ${ }^{\circledR}$, Lilly, USA) were initially reconstituted in sample buffer (10mM sodium phosphate, $\mathrm{pH}=7$ ) to a concentration of $2 \mathrm{mg} / \mathrm{mL}$. The High Oxidation hGH sample was prepared by addition of hydrogen peroxide to a final concentration of $0.5 \%(\mathrm{v} / \mathrm{v})$, then incubated under $37^{\circ} \mathrm{C}$ overnight. After the incubation, the High Oxidation hGH was dialyzed back into sodium phosphate sample buffer, to avoid further oxidation. G-CSF, with an initial concentration at 0.6 $\mathrm{mg} / \mathrm{mL}$ (Neupogen ${ }^{\circledR}$, Amgen, USA) were dialyzed into sample buffer (20mM glutamic acid with $5 \%$ sorbitol, w/v, $\mathrm{pH}=4.4$ ). The High Oxidation G-CSF sample was prepared by addition of hydrogen peroxide to a final concentration of $0.5 \%(\mathrm{v} / \mathrm{v})$, then incubated under $37^{\circ} \mathrm{C}$ for 2 hours. The High Oxidation G-CSF was dialyzed back into glutamic acid sample buffer. Dialyzation was performed with $200 \mu \mathrm{L}$ buffer at $13,000 \mathrm{rpm}$ for 20 minutes in a $500 \mu \mathrm{L} 10 \mathrm{kDa}$ Amicon (EMD Millipore Corporation, Merck, Germany) centrifugal filter, which was repeated three times. The Medium Oxidation samples of hGH and G-CSF were 40\%:60\% mixtures of the High Oxidation and Control samples. Control, Medium Oxidation and High Oxidation samples were all lyophilized overnight. Upon testing, all samples were reconstituted to a final concentration of 2 $\mathrm{mg} / \mathrm{mL}$ of hGH and $0.6 \mathrm{mg} / \mathrm{mL}$ of G-CSF, and stored at $-80{ }^{\circ} \mathrm{C}$ for further use.

\section{SI-8. Measurement of degree of oxidation by mass spectrometry}


$50 \mu \mathrm{g}$ hGH sample was dissolved in $6 \mathrm{M}$ guanidinium chloride and reduced by $10 \mathrm{mM}$ dithiothreitol under $70{ }^{\circ} \mathrm{C}$ for 30 minute, which was followed by alkylation with $55 \mathrm{mM}$ iodoacetamide under room temperature in dark condition. Proteins were dialyzed to Tris- $\mathrm{HCl}$ buffer ( $\mathrm{pH}=6.8$ ) with a $10 \mathrm{kD}$ membrane Amicon centrifugal filter at 13,000 rmp for 15 minutes, which was repeated three times. The following in-solution digestion process with Trypsin was kept overnight at room temperature to avoid artificial oxidation. The digestion was terminated by addition of $20 \mu \mathrm{L} 5 \%$ formic acid. $50 \mu \mathrm{g}$ G-CSF sample was adjusted to a $\mathrm{pH}$ of 3 by $\mathrm{HCl}$, followed by digestion with pepsin at $37^{\circ} \mathrm{C}$ for 30 minutes. The digestion process was terminated by adjusting the $\mathrm{pH}$ to 8 by $0.1 \mathrm{M} \mathrm{NH}_{4} \mathrm{CO}_{3}$. Proteins were then ready for LC-MS analysis, the remaining materials were aliquot to $20 \mu \mathrm{L}$ and stored in $-80{ }^{\circ} \mathrm{C}$ for further analysis.

LC-MS analysis used an Ultimate 3000 nano LC pump (Dionex, Mountain View, CA) and selfpacked C18 column (Magic C18, 200Å pore and $5 \mu \mathrm{m}$ particle size, $75 \mu \mathrm{m}$ internal diameter by $100 \mathrm{~mm}$ ) connected to a coated emitter with an internal diameter of $10 \mu \mathrm{m}$ (New Objective, Woburn, MA). LTQ-Orbitrap XL mass spectrometer (Thermo Fisher Scientific, San Jose, CA) was connected through a nanospray ion source (New Objective, Woburn, MA). $0.1 \%$ formic acid in HPLC grade water was used as Mobile Phase A and $0.1 \%$ formic acid in acetonitrile was used as Mobile Phase B. During sample injection, the flow rate was set to $250 \mathrm{~nL} / \mathrm{min}$ with $2 \%$ B for $25 \mathrm{~min}$. The flow rate of the gradient was set to $200 \mathrm{~nL} / \mathrm{min}$, with mobile phase B, 0-60 $\mathrm{min} 40 \%$, 60-70 $\min 90 \%, 70-75 \min 90 \%$ and 75-78 $\min 2 \%$. The mass spectrometer was operated in a data dependent mode to switch between MS and CID-MS ${ }^{2}$. Briefly, after a full-scan MS spectrum from $\mathrm{m} / \mathrm{z} 400-2000$ in the ion-trap, 8 CID-MS ${ }^{2}$ activation steps were performed on the 8 most intense precursor ions from the full scan. All control and variants samples were run in triplicate.

For peptide identification, raw data were searched against human growth hormone and granulocyte-colony stimulating factor sequence using SEQUEST incorporated in Proteomic Discover 1.4 (Thermo Fisher Scientific). Peptide precursor ion mass tolerance was set to 1.0 Da, and the fragment ion mass tolerance 1.0 Da. Oxidation of Methionine residues were set as a potential dynamic modification. The identified peptides were then filtered using Xcorr score $\left(1^{+}\right.$ precursor ion $>1.9,2^{+}>2.2$, and $3^{+}$and above $>3.4$ ). Mass accuracy was set to $<50 \mathrm{ppm}$. Final confirmation of the peptide identification was determined by manual inspection, extracting the base peak from the chromatogram and matching the $\mathrm{MS}^{2}$ fragmentation data with theoretical prediction. The oxidation percentage was calculated by peptide peak area.

\section{SI-9. Processing of fluorescence images}


In our data processing, we quantified each signal band by its total area, not the intensity of peak at a particular point. The data processing was performed with ImagJ and OriginPro 9.1, as described below. The raw data of hGH competitive assay (Fig. 2(b), left sub-figure) was used as an example.

a). Background intensity is measured by choosing a region of interest (ROI) in the channel far from the EC region. The background intensity is 77.5.

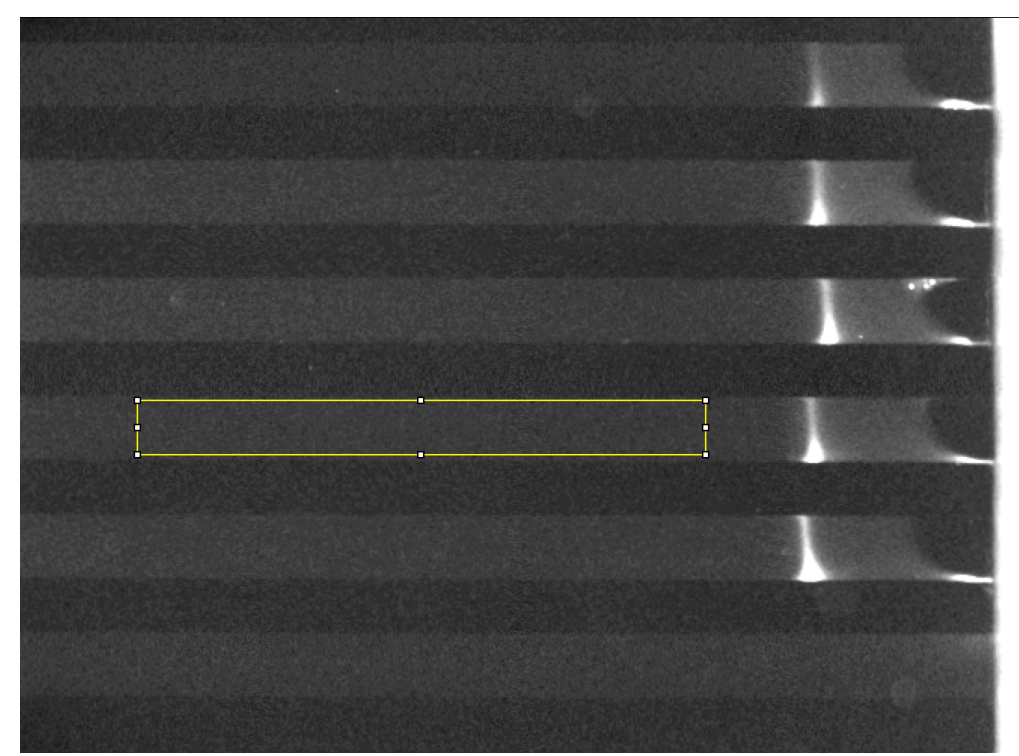

a-1). ROI for background subtraction on the raw image.

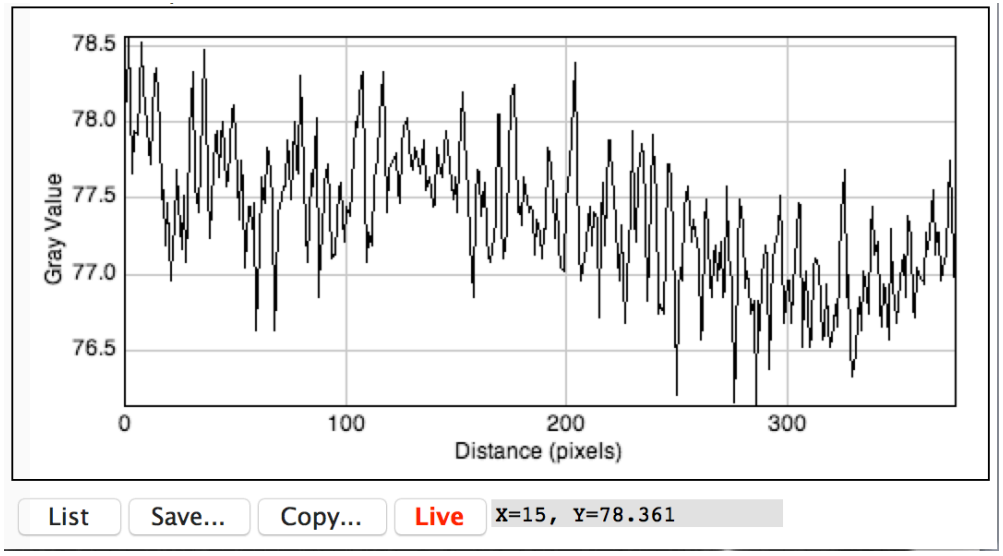

a-2). Background intensity. 
b). Background is subtracted from the whole image using ImageJ (Process- $>$ Math$>$ Substract). The ion depletion region has an intensity lower than background, which becomes negative after background subtraction. The negative values are automatically reset to 0 by ImageJ, which helps to create a uniform background.

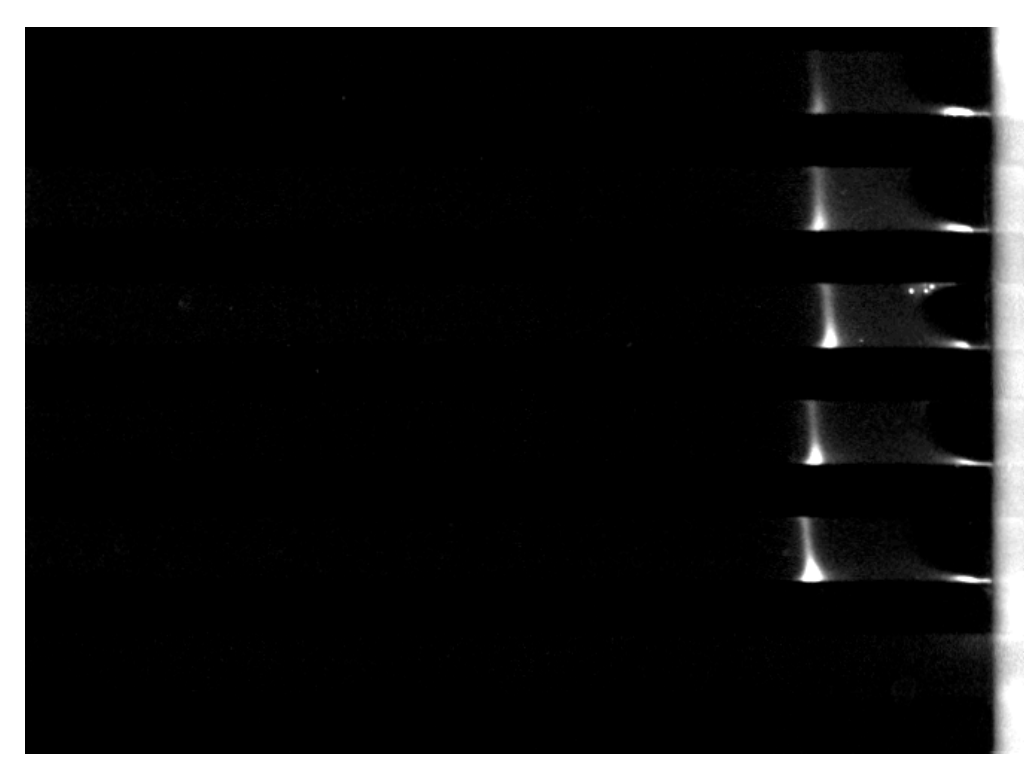

b-1). Image after background subtraction.

c). For each channel, a ROI of the channel width covering the two bands is chosen, giving the profile of the two bands. Note that each point on the profile represents the average across the channel width. Therefore, the area of each band represents the total amount of molecule of interest in each band. 


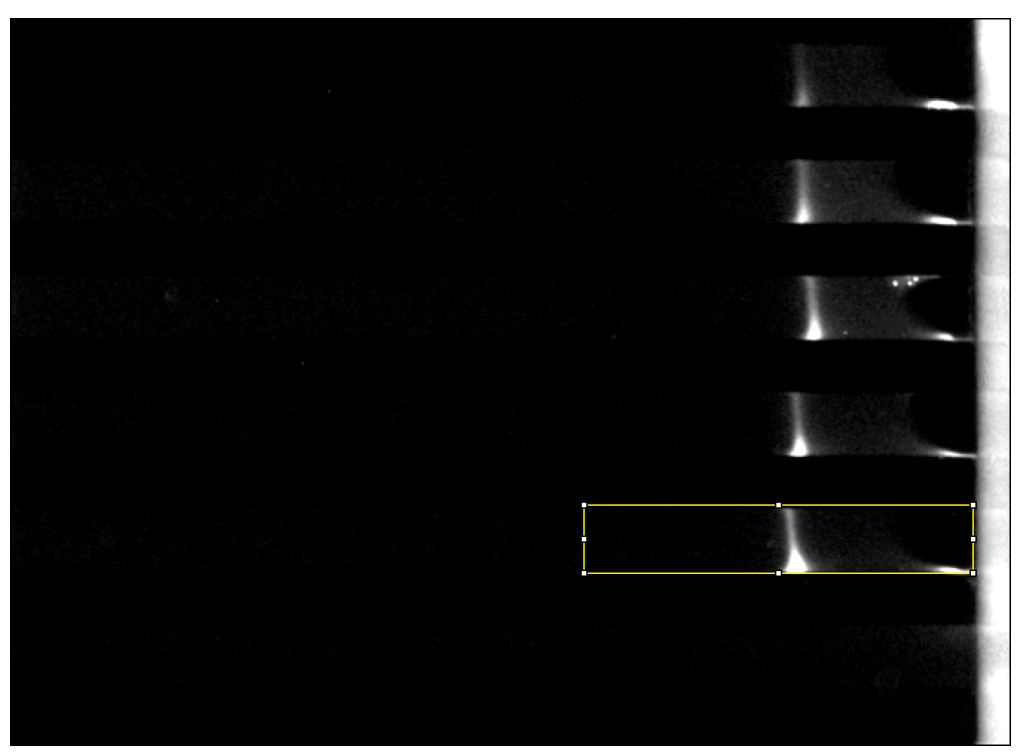

c-1). ROI for measuring the profile of the bands.

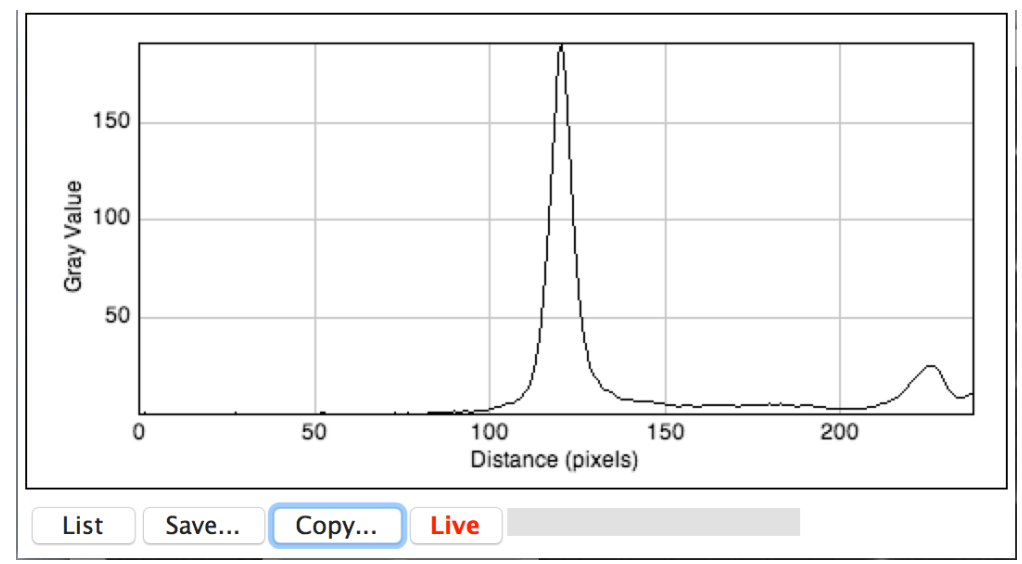

c-2). Profile of the two bands in each channel.

d). The band area was integrated using OriginPro 9.1 (Analysis->Peaks and Baselines$>$ Peak Analyzer). The relative ratio of the band areas is used for quantification of binding, as introduced in the paper. 


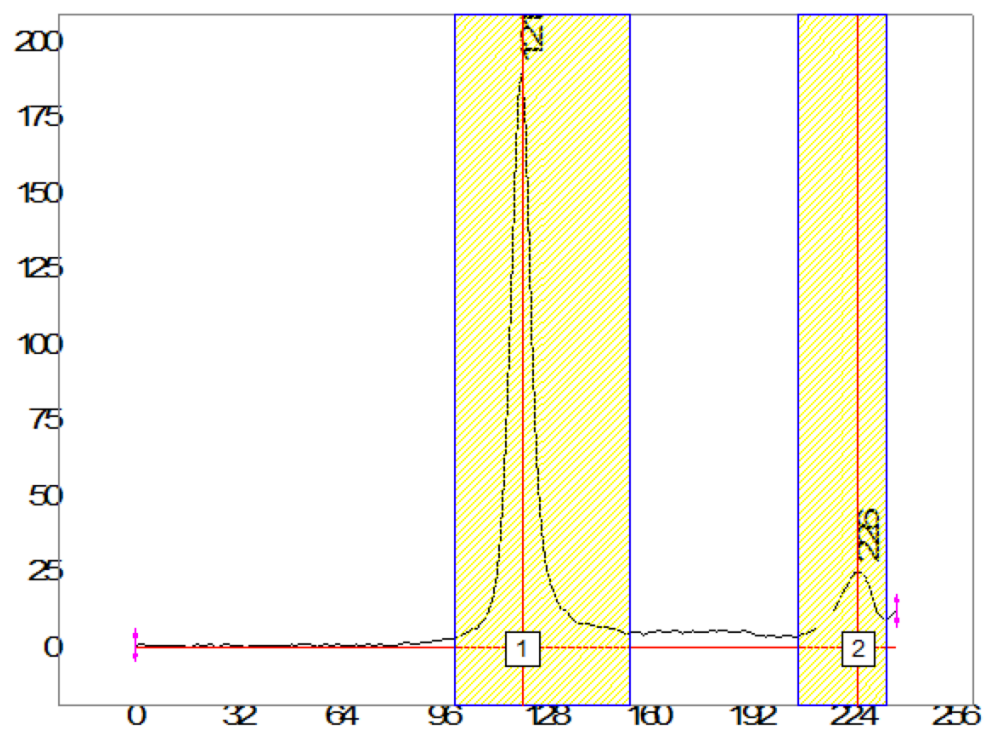

d-1). Integration of band area using OriginPro 9.1.

\begin{tabular}{|c|c|c|c|c|c|c|c|c|}
\hline Index & Area & ArealntgP(\%) & Row Index & Beginning $X$ & Ending $X$ & FWHM & Center & Height \\
\hline Integral Result of B & Integral Result of $\mathrm{B}$ & Integral Result of B & Integral Result of $\mathrm{B}$ & Integral Result of B & Integral Result of $\mathrm{B}$ & Integral Result of $\mathrm{B}$ & Integral Result of B & Integral Result of $\mathrm{B}$ \\
\hline 1 & 1904.70335 & 72.16879 & 121 & 100 & 155 & 7.48631 & 121 & 189.7813 \\
\hline 2 & 374.70325 & 14.19742 & 227 & 207 & 235 & 13.15897 & 227 & 24.875 \\
\hline
\end{tabular}

d-2). Integral result of band areas.

\section{SI-10. Binding kinetics measured by Octet RED 96}

The binding kinetics of hGH, IFN $\alpha 2 \mathrm{~b}$, and G-CSF was measured by Octet RED 96. The buffer used was 1xPBS with $1 \%$ BSA. First, Ni-NTA sensor tips were dipped into $20 \mathrm{ug} / \mathrm{ml} \mathrm{GHR,} \mathrm{IFNR,}$ and GCSFR (all with his-tags) for ligand immobilization. Next, association was conducted, with loaded sensor tips dipped into different concentrations of hGH, IFNa2b, and G-CSF. Finally, dissociation was conducted by dipping the sensor tips into the buffer.

\section{1 binding kinetics of hGH}




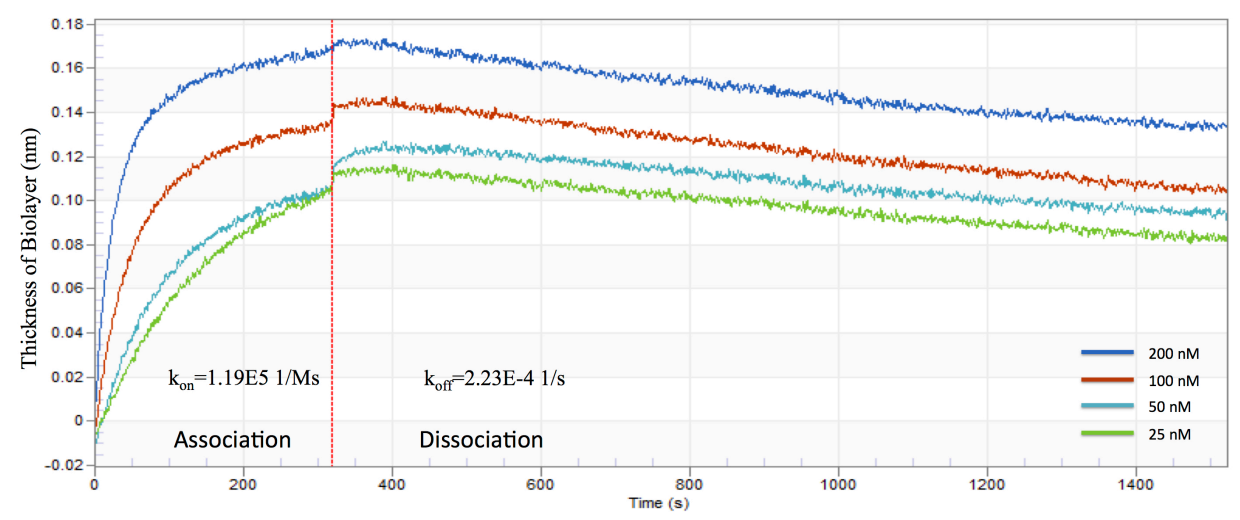

(a) Sensorgram of the binding kinetics of hGH by Octet RED 96.

(b) Binding kinetics of hGH.

\begin{tabular}{|c|c|c|c|c|c|c|}
\hline \# & $\mathrm{k}_{\mathrm{on}}(1 / \mathrm{Ms})$ & $\begin{array}{c}\text { average } \mathrm{k}_{\text {on }} \\
(1 / \mathrm{Ms})\end{array}$ & $\mathrm{k}_{\mathrm{off}}(1 / \mathrm{s})$ & $\begin{array}{c}\text { average } \mathrm{k}_{\mathrm{off}} \\
(1 / \mathrm{s})\end{array}$ & $\mathrm{K}_{\mathrm{D}}(\mathrm{nM})$ & $\begin{array}{c}\text { average } K_{D} \\
(n M)\end{array}$ \\
\hline 1 & $1.19 \mathrm{E} 5$ & \multirow{3}{*}{$(2.40 \pm 1.05) \mathrm{E} 5$} & $2.23 \mathrm{E}-4$ & \multirow{3}{*}{$\begin{array}{c}(2.05+0.23) \mathrm{E}- \\
4\end{array}$} & 1.88 & \multirow{3}{*}{$1.07 \pm 0.71$} \\
\hline 2 & $2.90 \mathrm{E} 5$ & & $2.14 \mathrm{E}-4$ & & 0.74 & \\
\hline 3 & $3.10 \mathrm{E} 5$ & & $1.79 \mathrm{E}-4$ & & 0.58 & \\
\hline
\end{tabular}

\section{2 binding kinetics of IFNa2b}

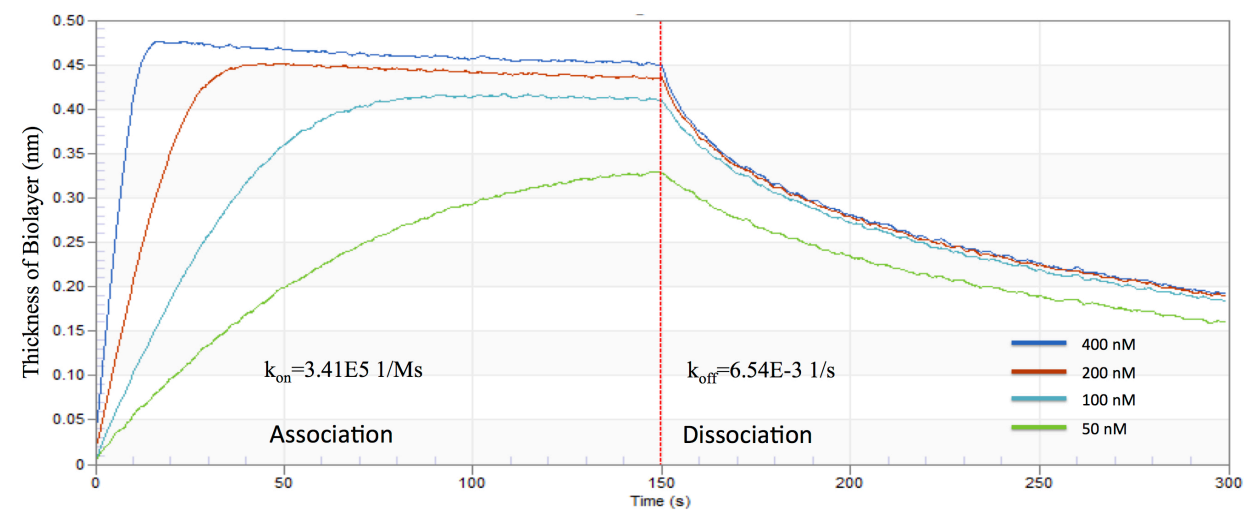

(c) Sensorgram of the binding kinetics of IFN $\alpha 2$ b by Octet RED 96.

(d) Binding kinetics of IFNa2b. 


\begin{tabular}{|c|c|c|c|c|c|c|}
\hline \# & $\mathrm{k}_{\text {on }}(1 / \mathrm{Ms})$ & $\begin{array}{c}\text { average } \mathrm{k}_{\text {on }} \\
(1 / \mathrm{Ms})\end{array}$ & $\mathrm{k}_{\text {off }}(1 / \mathrm{s})$ & $\begin{array}{c}\text { average } \mathrm{k}_{\text {off }} \\
(1 / \mathrm{s})\end{array}$ & $\mathrm{K}_{\mathrm{D}}(\mathrm{nM})$ & $\begin{array}{c}\text { average } \mathrm{K}_{\mathrm{D}} \\
(\mathrm{nM})\end{array}$ \\
\hline 1 & $3.41 \mathrm{E} 5$ & \multirow{3}{*}{$(4.09+0.72) \mathrm{E} 5$} & $6.54 \mathrm{E}-3$ & \multirow{3}{*}{$\begin{array}{c}(8.97+3.05) \mathrm{E}- \\
3\end{array}$} & 19.2 & \multirow{3}{*}{$22.2 \pm 7.65$} \\
\hline 2 & $4.85 \mathrm{E} 5$ & & $7.98 \mathrm{E}-3$ & & 16.5 & \\
\hline 3 & $4.02 \mathrm{E} 5$ & & $1.24 \mathrm{E}-2$ & & 30.9 & \\
\hline
\end{tabular}

\section{3 binding kinetics of G-CSF}

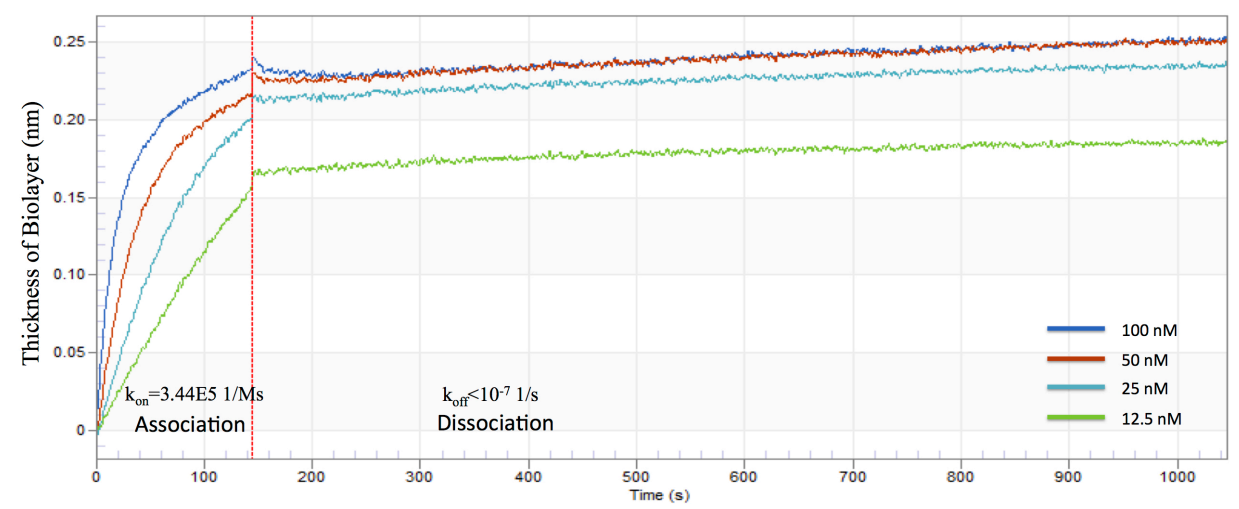

(e) Sensorgram of the binding kinetics of G-CSF by Octet RED 96.

The dissociation rate of G-CSF is $<10^{-4} 1 / \mathrm{s}$, so dissociation could hardly be observed during the experiment time (1000 s). During the dissociation step, the thickness of the bio-layer did not decrease but increased due to non-specific adsorption, which resulted in an unreliable result of $k_{\text {off }}<10^{-7} 1 / \mathrm{s}$. Consequently, the $K_{D}$ of G-CSF measured by Octet RED 96 was $<1 \mathrm{pM}$, which deviated significantly from the actual value.

\section{SI-11. Classic second-order binding model}




$$
\begin{aligned}
& \text { TP } \quad+\quad \text { TPR } \rightarrow \quad \text { TP-TPR } \\
& \begin{array}{llll}
\text { Initial: } & \mathrm{c}_{\mathrm{TP}} & \mathrm{c}_{\mathrm{TPR}} & 0
\end{array} \\
& \text { Equilibrium: } \quad \mathrm{c}_{\mathrm{TP}}-\mathrm{c}_{\mathrm{TP}-\mathrm{TPR}} \quad \mathrm{c}_{\mathrm{R}}-\mathrm{c}_{\mathrm{TP}-\mathrm{TPR}} \quad \mathrm{c}_{\mathrm{TP} \text { TPR }} \\
& k_{D}=\frac{\left(c_{T P}-c_{T P-T P R}\right)\left(c_{T P R}-c_{T P-T P R}\right)}{c_{T P-T P R}} \\
& c_{T P-T P R}=\frac{\left(c_{T P}+c_{T P R}+k_{D}\right)-\sqrt{\left(c_{T P}+c_{T P R}+k_{D}\right)^{2}-4 c_{T P} c_{T P R}}}{2} \\
& \%\left(B o u n d_{-} T P R\right)=\frac{c_{T P-T P R}}{c_{T P R}}=\frac{\left(c_{T P}+c_{T P R}+k_{D}\right)-\sqrt{\left(c_{T P}+c_{T P R}+k_{D}\right)^{2}-4 c_{T P} c_{T P R}}}{2 c_{T P R}}
\end{aligned}
$$

The binding between TP and TPR is described by the classic second-order binding model. According to the definition of $K_{D}$ in Equation SI-11-1, the concentration of the TP-TPR complex $c_{T P-T P R}$ can be solved as Equation SI-11-2. The degree of binding is characterized by the percentage of receptor that is bound to TP [\%(Bound-TPR)], which is expressed as Equation SI11-3. Equation SI-11-3 shows the relation of the concentration of TP and the degree of binding, with the concentration of receptor $c_{T P R}$ and $K_{D}$ as parameters. By fitting experimental results with Equation SI-11-3, $K_{D}$ can be extracted. In practice, the concentration corresponding to a degree of binding of $50 \%$ is widely used as the apparent $K_{D}$, which can be directly read from the fitted dose-response curve.

\section{SI-12. Equal- $K_{D}$ curve of the competitive assay}

The dose-response curve of a competitive assay is difficult to derive directly when the test and reference TP have different $K_{D}$ 's. However, in the case that the $K_{D}$ of test molecule equals that of its reference molecule, the theoretical dose-response curve can be readily calculated based on the ratio of test and reference molecules. 


$$
\begin{aligned}
& \text { TP } \quad+\quad \text { TPR } \rightarrow \quad \text { TP-TPR } \\
& \text { Initial: } \mathrm{c}_{\mathrm{TP}} \quad \mathrm{c}_{\mathrm{TPR}} \quad 0 \\
& \text { Equilibrium: } \quad \mathrm{c}_{\mathrm{TP}} \mathrm{c}_{\mathrm{TP}-\mathrm{TPR}} \quad \mathrm{c}_{\mathrm{R}}-\mathrm{c}_{\mathrm{TP}-\mathrm{TPR}} \quad \mathrm{c}_{\mathrm{TP} \text {-TPR }} \\
& c_{T P}=c_{T P}^{r e f}+c_{T P}^{t e s t} \\
& \text { Assuming equal } \mathrm{k}_{\mathrm{D},} \quad k_{D}^{\text {ref }}=k_{D}^{\text {test }} \\
& c_{T P}^{r e f}(\text { bound })=c_{T P-T P R} \cdot \frac{c_{T P}^{r e f}}{c_{T P}^{r e f}+c_{T P}^{\text {test }}} \\
& \%\left(\text { bound_ } c_{T P}^{r e f}\right)=\frac{c_{T P}^{r e f}(\text { bound })}{c_{T P}^{r e f}} \\
& =\frac{\left(c_{T P}+c_{T P R}+k_{D}\right)-\sqrt{\left(c_{T P}+c_{T P R}+k_{D}\right)^{2}-4 c_{T P} c_{T P R}}}{2 c_{T P R}} \cdot \frac{1}{c_{T P}^{r e f}+c_{T P}^{\text {test }}} \\
& \text { In special cases when } \mathrm{c}_{\mathrm{TP}}>=\mathrm{c}_{\mathrm{TPR}}>>\mathrm{k}_{\mathrm{D}} \text {, } \\
& c_{T P-T P R} \approx c_{T P R} \\
& \%\left(\text { bound } \_c_{T P}^{r e f}\right)=\frac{c_{T P}^{r e f}(\text { bound })}{c_{T P}^{r e f}}=\frac{c_{T P R}}{c_{T P}^{r e f}+c_{T P}^{\text {test }}}
\end{aligned}
$$

In a competitive assay, the total concentration of TP $c_{T P}$ is comprised of the concentration of the labeled reference TP $c_{T P}{ }^{r e f}$ and the test TP $c_{T P}{ }^{\text {test }}$ (Equation SI-12-1). Assume that the reference and test TP have the same $K_{D}$, which means the reference and test TP have equal chances of binding to TPR. Therefore, the concentration of the reference TP that is bound to TPR $c_{T P}{ }^{r e f}$ (bound) is the concenstration of the TP-TPR complex $c_{T P-T P R}$ multiplied by the percentage of the reference TP in total TP (Equation SI-12-3). The percentage of reference TP that is bound to TPR $\%\left(\right.$ bound_c $\left.c_{T P}^{r e f}\right)$ can be directly expressed as Equation SI-11-4. In special cases when $c_{T P}>=c_{T P R}>>K_{D}$, such as the hGH and G-CSF competitive assay in this work, \%(bound_c $c_{T P}^{r e f}$ ) can be reduced to Equation SI-12-6, which clearly shows that higher concentrations of test TP reduce the binding of reference TP to TPR due to competitive binding. The theoretical equal- $K_{D}$ curve can be directly plotted using Equations SI-12-4 and SI-12-6.

\section{SI-13. Calculation of the relative activity in the degradation-determination assay}

The Relative Activity (R.A.) of the test TP to the reference TP was defined and calculated as the following, 
$\mathrm{TP}^{*} \quad+$ TPR $\rightarrow$ TP*TPR $\quad$ TP $\quad+\quad$ TPR $\rightarrow$ TP-TPR

Initial: $\quad \mathrm{c}_{0}$

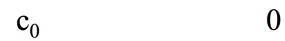

$\mathrm{c}_{0}$

$\mathrm{c}_{0}$

0

Equilibrium: $c_{0}-c_{\text {bound }}^{r e f} \quad c_{0}-c_{\text {bound }}^{r e f}-c_{\text {bound }}^{\text {tgt }} \quad c_{\text {bound }}^{\text {ref }} \quad c_{0}-c_{\text {bound }}^{\text {test }} \quad c_{0}-c_{\text {bound }}^{\text {ref }}-c_{\text {bound }}^{\text {test }} \quad c_{\text {bound }}^{\text {test }}$

$$
\begin{aligned}
& k_{D}^{\text {ref }}=\frac{\left(c_{0}-c_{\text {bound }}^{\text {ref }}\right)\left(c_{0}-c_{\text {bound }}^{\text {ref }}-c_{\text {bound }}^{\text {test }}\right)}{c_{\text {bound }}^{\text {ref }}} \\
& k_{D}^{\text {tgt }}=\frac{\left(c_{0}-c_{\text {bound }}^{\text {tgt }}\right)\left(c_{0}-c_{\text {bound }}^{\text {ref }}-c_{\text {bound }}^{\text {test }}\right)}{c_{\text {bound }}^{\text {tgt }}}
\end{aligned}
$$

In the case of $\mathrm{c}_{0}>>K_{D}{ }^{\text {ref }}$ or $K_{D}^{\text {test }}, \quad c_{\text {bound }}^{\text {ref }}+c_{\text {bound }}^{\text {test }} \approx c_{0}$

$$
\frac{k_{D}^{\text {ref }}}{k_{D}^{\text {test }}}=\frac{c_{\text {bound }}^{\text {test }}\left(c_{0}-c_{\text {bound }}^{\text {ref }}\right)}{c_{\text {bound }}^{\text {ref }}\left(c_{0}-c_{\text {bound }}^{\text {test }}\right)}=\left(\frac{c_{0}-c_{\text {bound }}^{\text {ref }}}{c_{\text {bound }}^{\text {ref }}}\right)^{2}
$$

Define Relative Activity (R.A.) of test TP to reference TP as,

$$
R . A .=\frac{k_{D}^{\text {ref }}}{k_{D}^{\text {test }}}=\left(\frac{1-c_{\text {bound }}^{\text {ref }} / c_{0}}{c_{\text {bound }}^{\text {ref }} / c_{0}}\right)^{2}=\left(\frac{1-\% \operatorname{REF}(\text { Bound })}{\% \operatorname{REF}(\text { Bound })}\right)^{2}
$$

where $K_{D}{ }^{\text {ref }}, K_{D}{ }^{\text {test }}$ and $\% \operatorname{REF}$ (Bound) are the $K_{D}$ of the reference TP, the $K_{D}$ of the target TP, and percentage of the reference TP in bound state, respectively. 